\title{
Do the rich get richer? Varying effects of tree species identity and diversity on the richness of understory taxa
}

\author{
Juliette Chamagne, ${ }^{1,8}$ C. E. Timothy Paine, ${ }^{2}$ Donald R. Schoolmaster Jr. $_{5}{ }^{3}$ Robert Stejskal, ${ }^{4}$ \\ Daniel Volařík, ${ }^{4}$ Jan Šebesta, ${ }_{4}^{4}$ Filip Trnka, ${ }^{5}$ Tomáš Koutecký, ${ }^{4}$ Petr Švarc, ${ }^{6}$ Martin Svátek, \\ Andy Hector, ${ }^{1,7}$ and Radim Matula ${ }^{4}$ \\ ${ }^{1}$ Institute of Evolutionary Biology and Environmental Studies, University of Zurich, Winterthurerstrasse 190, CH-8057, Zurich, \\ Switzerland \\ ${ }^{2}$ Biological and Environmental Sciences, University of Stirling, Stirling, FK9 4LA, United Kingdom \\ ${ }^{3}$ Wetland and Aquatic Research Center, U.S. Geological Survey, Lafayette, Louisiana 70506 USA \\ ${ }^{4}$ Department of Forest Botany, Dendrology and Geobiocoenology, Faculty of Forestry and Wood Technology, Mendel University in \\ Brno, Zemédělská 3, 613 00, Brno, Czech Republic \\ ${ }^{5}$ Department of Ecology and Environmental Sciences, Faculty of Science, Palacký University Olomouc, Šlechtitelů 27, CZ-783 71, \\ Olomouc, Czech Republic \\ ${ }^{6}$ Department of Forest Protection and Wildlife Management, Faculty of Forestry and Wood Technology, Mendel University in Brno, \\ Zemědělská 3, 613 00, Brno, Czech Republic \\ ${ }^{7}$ Department of Plant Sciences, University of Oxford, Oxford OX1 3RB United Kingdom
}

\begin{abstract}
Understory herbs and soil invertebrates play key roles in soil formation and nutrient cycling in forests. Studies suggest that diversity in the canopy and in the understory are positively associated, but these studies often confound the effects of tree species diversity with those of tree species identity and abiotic conditions. We combined extensive field sampling with structural equation modeling to evaluate the simultaneous effects of tree diversity on the species diversity of understory herbs, beetles, and earthworms. The diversity of earthworms and saproxylic beetles was directly and positively associated with tree diversity, presumably because species of both these taxa specialize on certain species of trees. Tree identity also strongly affected diversity in the understory, especially for herbs, likely as a result of interspecific differences in canopy light transmittance or litter decomposition rates. Our results suggest that changes in forest management will disproportionately affect certain understory taxa. For instance, changes in canopy diversity will affect the diversity of earthworms and saproxylic beetles more than changes in tree species composition, whereas the converse would be expected for understory herbs and detritivorous beetles. We conclude that the effects of tree diversity on understory taxa can vary from positive to negative and may affect biogeochemical cycling in temperate forests. Thus, maintaining high diversity in temperate forests can promote the diversity of multiple taxa in the understory.
\end{abstract}

Key words: biodiversity; detritivorous beetles; earthworms; ecosystem functioning; herbs; predatory beetles; saproxylic beetles; structural equation model; temperate forests; trees.

\section{INTRODUCTION}

The ongoing loss of biodiversity induced by human activities has led ecologists to assess its consequences for ecosystems, and the services that they provide humanity (Naeem et al. 2009, Rockström et al. 2009, Cardinale et al. 2012). In grasslands, increased plant diversity often leads to increased productivity and decomposition (Hooper et al. 2012). The positive effect of diversity arises from both among-species complementarity and speciesspecific impacts on ecosystem processes (Loreau and Hector 2001). Although the importance of forests for both biodiversity and ecosystem services is widely recognized, biodiversity studies are more difficult to mount in forests due the great size and lifespan of trees (Nadrowski et al. 2010). Although recent work has shown that

Manuscript received 7 April 2016; revised 3 May 2016; accepted 6 May 2016. Corresponding Editor: E. L. Preisser.

${ }^{8}$ E-mail: juliettechamagne@gmail.com biodiversity in forests promotes tree growth and ecosystem stability (Zhang et al. 2012, Jucker et al. 2014), the relationships between tree diversity and the diversity of understory organisms such as soil invertebrates and herbaceous plants are little known (Wardle et al. 2004, van der Heijden et al. 2008).

Earthworms and other soil invertebrates play crucial roles in litter decomposition, a key process for nutrient and carbon cycling in most terrestrial ecosystems (Aerts 1997). They affect plant growth directly by feeding on roots (Scheu 2003), and indirectly by altering soil structure, nutrient availability, and the activity of soil microorganisms (Wardle 1999, Scheu 2003, Wurst et al. 2003, Partsch et al. 2006). Understory herbaceous plants, though they contribute only $0.2 \%$ of total forest biomass (Gilliam 2007), generate $4 \%$ of forest net primary production and up to $16 \%$ of foliar litter, with greater nutrient content and more rapid decomposition than the tree-leaf litter (Muller 2003). As a result, 
impacts of tree diversity on the diversity of understory organisms have the potential to alter forest carbon and nutrient cycling.

Tree diversity often positively affects the diversity of understory invertebrates and herbs (Nadrowski et al. 2010). For example, herb species richness increased with increasing tree diversity in a central European forest, and decreased with canopy cover and humus mass (Vockenhuber et al. 2011). Tree diversity was also associated with increased earthworm and beetle diversity (Cesarz et al. 2007, Sobek et al. 2009b). The two mechanisms invoked to link their diversity are an increase in the heterogeneity of soil conditions (Cesarz et al. 2007, Sobek et al. 2009b, Vockenhuber et al. 2011), and differential facilitation effects of each tree species on certain understory species (Augusto et al. 2003, Lassau et al. 2005).

The identity of tree species can indirectly affect understory diversity by altering abiotic conditions. Tree species that differ in their rates of crown light transmittance, litter chemistry, and decomposition also differ in their impact on forest soil, litter, and light properties (Hobbie et al. 2006, Barbier et al. 2008). In Europe, for instance, European beech (Fagus sylvatica L.) and conifers are generally associated with low herbaceous plant diversity (Cesarz et al. 2007, Barbier et al. 2008, Sobek et al. 2009b). Soil and litter properties significantly impact the diversity of earthworms, soil beetles, and herb species (Ponge et al. 1999, Wardle et al. 2004, Vockenhuber et al. 2011), and light availability often limits herb species richness (Kirby 1988, Jennings et al. 1999, Hofmeister et al. 2009).

Tree diversity, tree species identity, and abiotic conditions all affect the diversity of understory organisms, yet no study has explored their simultaneous effects, rendering it impossible to determine their relative importance (Mölder et al. 2008, Sobek et al. 2009a). First, a dilution gradient, where one matrix species is always present, is the only one found in monocultures, and whose abundance is "diluted," is often used instead of a true diversity gradient, in which all possible species combinations are represented (Cesarz et al. 2007, Sobek et al. 2009b). This makes it difficult to distinguish the effects of tree diversity from those of tree identity. Second, studies carried out in natural forests can confound diversity effects with variation in abiotic conditions (Nadrowski et al. 2010). For example, a positive relationship between tree and herb diversity could arise from soil fertility promoting the diversity of both trees and herbs. In this contribution, we assess the effects of tree diversity on understory diversity while controlling for the effects of tree identity and abiotic variables. We sampled 45 stands in a managed forest of the Czech Republic, the canopy layers of which were dominated by all possible combinations of four tree species, i.e., the composition ranged from the monoculture of each species to the mixture of all four species. We investigated the effects of tree species diversity, tree identity, and abiotic conditions on the diversity of three taxa that are important for ecosystem functioning: litter-dwelling earthworms, litter-dwelling beetles, and understory herbs. Using structural equation modeling (Grace 2006), we distinguished the direct effects of trees on the understory from those mediated by abiotic conditions. We hypothesized that tree diversity would directly promote the diversity of all understory taxa. Such relationships have been reported for herbs (Vockenhuber et al. 2011), earthworms (Cesarz et al. 2007), and beetles (Sobek et al. 2009b) in single-taxon studies. We expected tree diversity and density to increase canopy cover, and canopy cover to decrease herb diversity (Vockenhuber et al. 2011). We also predicted the effect of soil variables on the diversity of all taxa. Soil $\mathrm{N}$ content is likely to increase the diversity of herbs (as long as there is no excess N accumulation; Gilliam 2006) and soil invertebrates, whereas humus mass should reduce them (Schmidt et al 2004; Vockenhuber et al. 2011). Soils with higher $\mathrm{pH}$ can harbor higher diversities of herbs (Augusto et al. 2003) and earthworms (Cesarz et al. 2007). Thus, we expected soil quality (which is related to higher $\mathrm{pH}$ and $\mathrm{N}$ content, and lower humus mass) to support increased diversity of all understory groups. We predicted that herb diversity would drive the diversity of the invertebrate taxa due to increased heterogeneity in food resources and habitat. Finally, we predicted that the diversity of predatory beetles would increase with diversity of other invertebrate taxa, again because of increasing heterogeneity in food resources.

\section{Materials And Methods \\ Experimental design}

The Training Forest Enterprise (TFE) is located north of Brno, Czech Republic at $49^{\circ} 3^{\prime} \mathrm{N}$ and $16^{\circ} 7^{\prime} \mathrm{E}$ and 310-560 $\mathrm{m}$ above sea level (Fig. 1). The annual mean temperature is $7.5^{\circ}-8.1^{\circ} \mathrm{C}$, the average annual precipitation is $528-685 \mathrm{~mm}$, and $360 \mathrm{~mm}$ during the growing season, and Cambisol is the main soil type (Truhlár ${ }^{2}$ 1997). The forest has been managed by Mendel University in Brno for a hundred years. Forest type, age, density, and volumetric species composition are estimated in each of the 4,000 stands every 10 years, and the data are publically available (available online). ${ }^{9}$ Forests of the TFE are dominated by an evergreen conifer, Picea abies (Norway spruce), a deciduous conifer, Larix decidua (European larch), and two broadleaved tree species, Quercus petraea and Fagus sylvatica (sessile oak and European beech, respectively). Out of the four species, Larix decidua is the only nonnative species, with the nearest native locality being in the extreme northeast of the Czech Republic (approximately $150 \mathrm{~km}$ away from FTE). In the most recent forest inventory (2012), these four species jointly represented $75 \%$ of timber volume of the TFE. We selected three stands of each of the 15 possible combinations of the four focal

\footnotetext{
${ }^{9}$ www.mapserver-slp.mendelu.cz/
} 


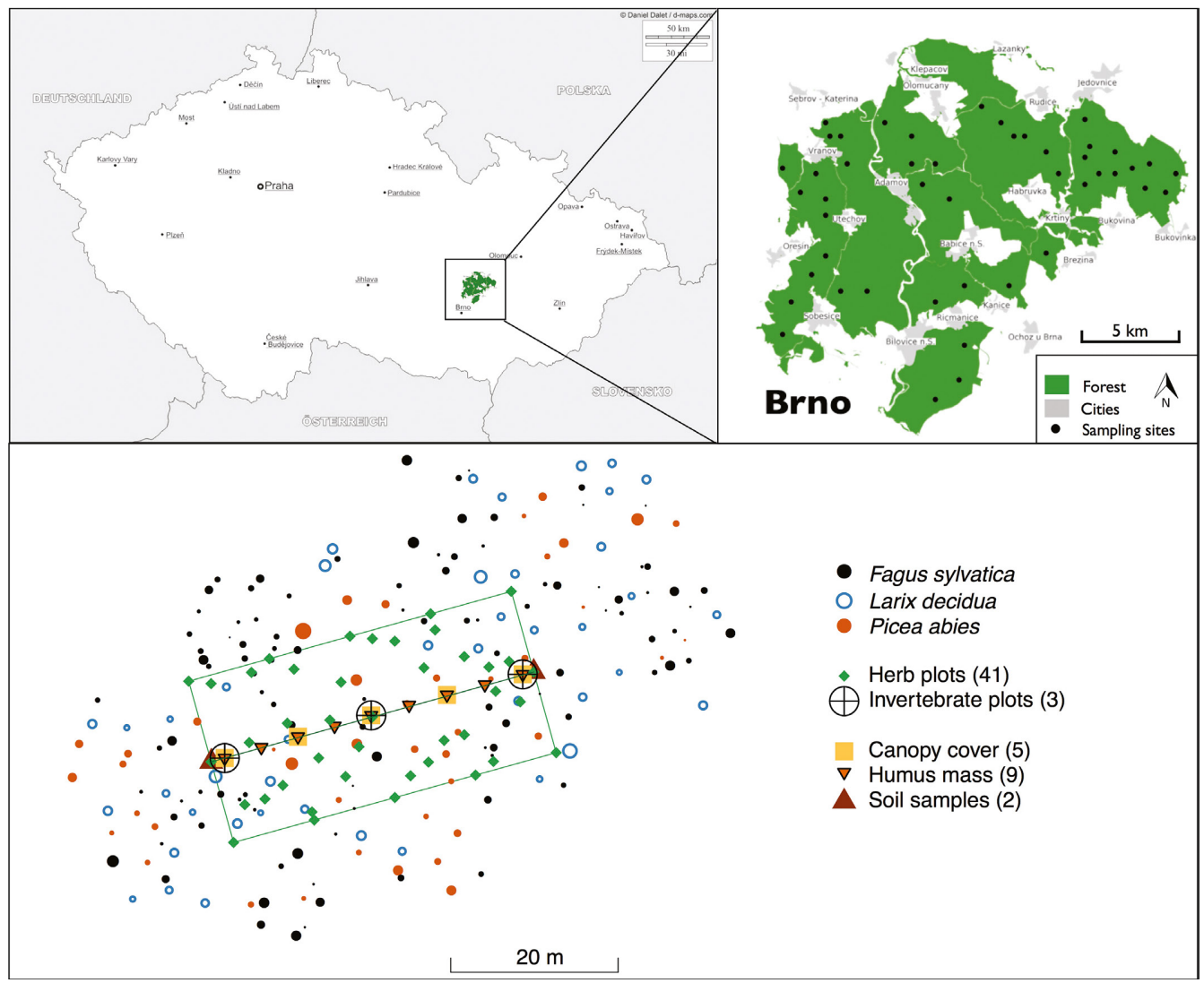

FIG. 1. The Training Forest Enterprise (TFE) is a managed forest located north of Brno, Czech Republic: $49^{\circ} 3^{\prime} \mathrm{N}$ and $16^{\circ} 7^{\prime} \mathrm{E}$. The bottom panel pictures a map of an example forest stand with three tree species dominating the canopy: Fagus sylvatica, Larix decidua, and Picea abies. The points marking canopy tree locations are proportional to their diameter at breast height (DBH; $1.3 \mathrm{~m})$. The $40 \times 20 \mathrm{~m}$ understory transect is indicated by a green rectangle, in which herbs were sampled at 41 plots. Invertebrates were sampled at both ends and at the midpoint of the transect. Canopy cover, humus mass, and soil attributes were collected at five, nine, and two locations along the transect, respectively.

species ( 45 stands, total). The stands were chosen in a way to minimize the range of abiotic features: all had Cambisol as a soil type, were flat or with a slight slope $(<10 \%)$, and were planted 50-100 years ago. Stands averaged 0.24 ha and ranged from 0.07 to 0.6 ha.

\section{Data collection}

In each stand, six trees of every focal species were targeted, and the positions of targets and their neighbors in a 10-m radius were mapped with Field-Map technology (Field-Map, Jilove u Prahy, Czech Republic). Every mapped tree was identified, and its diameter at breast height (DBH) measured. Tree diversity was calculated as the effective number of species, or the exponent of the Shannon index $e^{H^{\prime}}$ (Magurran 2004), which accounts for both species richness and evenness. Canopy tree density and the relative abundance of each species was calculated using basal area.

A $40 \times 20 \mathrm{~m}$ transect was established in the understory of every stand, along which herbs, beetles, earthworms, and abiotic conditions were assessed (Fig. 1). The direction of each transect was randomly determined. For herbs, $411-\mathrm{m}^{2}$ randomly located plots, divided into $20 \times 20 \mathrm{~cm}$ sub-grids (i.e., 25 sub-grids per plot), were established along all transects. In each plot, the relative abundance of each herb species was estimated by counting the number of sub-grids in which the species was present. A pilot study showed that sampling 41 plots was sufficient to saturate the species-accumulation curve.

Beetles and earthworms were sampled in $5 \mathrm{~m}$-radius plots at the ends and middle of each transect (Fig. 1). For each invertebrate sample, we collected humus (ground litter and leaf mold) in five randomly selected $30 \times 30 \mathrm{~cm}$ subplots. Humus was sifted using an entomological sifter with a $10-\mathrm{mm}$ wire-mesh screen bottom. Material sifted through the screen was exposed to the sun on a white cloth for about $15 \mathrm{~min}$, and beetles were manually collected. Large earthworms were collected prior to sifting, and small ones following sun exposure. We classified beetles by their feeding habits because we expected their responses to the tested variables to differ (Lassau et al. 2005). The three functional groups were predators, which feed on other animals; detritivores, which consume detritus; herbivores, 
which feed on live plants; and saproxylics, which live and feed on dead wood. For herbs, earthworms, and each functional group of beetles, gamma diversity was calculated as the total species richness per stand.

Finally, we assessed abiotic conditions including humus mass, canopy cover, and soil characteristics (Fig. 1). We assessed the mass of the humus layer by collecting, drying, and weighing humus from the top litter layer to the mineral soil from $100-\mathrm{cm}^{2}$ quadrats at nine points along each transect. Canopy cover was measured using hemispherical photographs taken with a Canon EOS 550 camera (Canon, Canon Inc., Tokyo, Japan.) with Sigma circular fish-eye lens (Sigma 4.5 mm F2.8 EX DC Circular Fisheye HSM; SIGMA CORPORATION, Kawasaki-shi, Kanagawa, Japan.) at five points along each transect. The hemispherical photographs were then analyzed using the Can-Eye V6.36 software (INRA, Paris, France.). Finally, soil samples were taken at both ends of each transect to assess nitrogen and phosphorus content, $\mathrm{pH}$, and catalase activity (i.e., the activity of microbial organisms). Herb, humus and canopy cover data were collected between July and August 2012, and beetles and earthworms in June 2012.

Soil quality.-To reduce the complexity of the model, we used principal components analysis (PCA) to reduce the number of soil variables. The first axis of a PCA that included $\mathrm{pH}$, nitrogen, and humus content explained $59 \%$ of the variation in these variables and was highly correlated with each of them $(\mathrm{pH}, r=0.88 ; \% \mathrm{~N}, r=0.64$; Humus, $r=-0.77)$. The scores from this axis were used as a single indicator of soil quality.

\section{Statistical analysis}

Causal hypotheses.-We used structural equation modeling (SEM, Grace 2006) to quantify the direct and indirect effects of canopy tree diversity, identity and density on the species richness of earthworms, beetles and herbs. We began by developing a causal diagram, which captured hypothesized causal relationships between the variables (Fig. 2) that are developed in the introduction. In addition, we included correlations between all pairs of tree species, because an increase in one species' abundance implies a reduction in the others in these closed-canopy forests. Each node in the causal diagram represents a concept that is causally related to one or more other concepts in the diagram. They are included to provide a comprehensive map of potentially important relationships and help identify potentially confounding relationships. Not all nodes in the causal diagram become observed variables, on which data is collected in the final model, but the presence of each node is used to inform parameter estimation of the statistical models.

Model updating and selection.-The analyses were conducted as follows. For each concept in Fig. 2, we assigned one or more variables from our observed data set (or calculated combination of these) to represent that concept (Appendix S1: Fig. S1). For each node in the model representing a random variable (i.e., a measured quantity; not one calculated without error from other measured quantities), we estimated its expected value as a function of each of the arrows pointing at it. Next, since the diagram is meant to capture all causal effects, each pair of variables not connected by an arrow is hypothesized to be conditionally independent (i.e., independent after accounting for the effect indicated by the arrows pointing at them). We used the set of pairs not connected by arrows to test the hypothesized structure. Pairs that were not conditionally independent were interpreted as errors in the hypothesized causal structure of the model. To test the conditional independence claims implied by the causal diagram, we chose the likely direction of causation between them, and we then parameterized the relationship between the variables and the probability that it differed from zero. We used Fisher's combined test (Fisher 1950) to combine these probabilities into a single test of the null hypothesis that the observed data were generated by a set of mechanisms given by the causal diagram (Shipley 2000). We then used the feedback obtained from fitting the initial model to update it. That is, we added arrows between pairs of variables that we first thought independent but were not, and we removed arrows between variables that we thought dependent but were not. Fitting the model in this manner, as opposed to using an automated SEM procedure, allowed us to choose appropriate error distributions for random variables.

All parameter estimation was performed in the R language and environment, version 3.1.2 (R Development Core Team 2011). We use generalized linear models to estimate the parameters of the random variables in Fig. S1 (Appendix S1). The distributions and link functions used for each variable are listed in Table S1 (Appendix $\mathrm{S} 1)$. For each of the species richness variables, we attempted to fit a negative binomial distribution using the glm.nb() function from the MASS package (Venables and Ripley 2002). In a few cases, this function failed to converge on stable estimates. When this occurred, we fit a Poisson distribution using the $\operatorname{glm}()$ function. We used Akaike information criterion (AIC) for model comparison. AIC was calculated using the log-likelihood of the joint distribution factorized by the causal graphical model. For these calculations, the basal area of each tree species assumed to follow a zero-inflated lognormal distribution. In the final model, we calculated $R^{2}$ for each endogenous (response) variable. For non-Gaussian models, we calculated a pseudo- $R^{2}$ as $1-e^{-2\left(\mathbf{L L}_{\text {full }}-\mathbf{L L}_{\text {null }}\right) / n}$, where $\mathrm{LL}_{\text {full }}$ is the log-likelihood of the full model, $\mathrm{LL}_{\text {null }}$ is the log likelihood of the intercept-only model, and $n$ is the sample size (Shtatland and Barton 1998).

\section{RESUlts}

In total, we found 181 herb species (mean per stand 26.8, range 1-50), six earthworm species (mean 2.4 per 


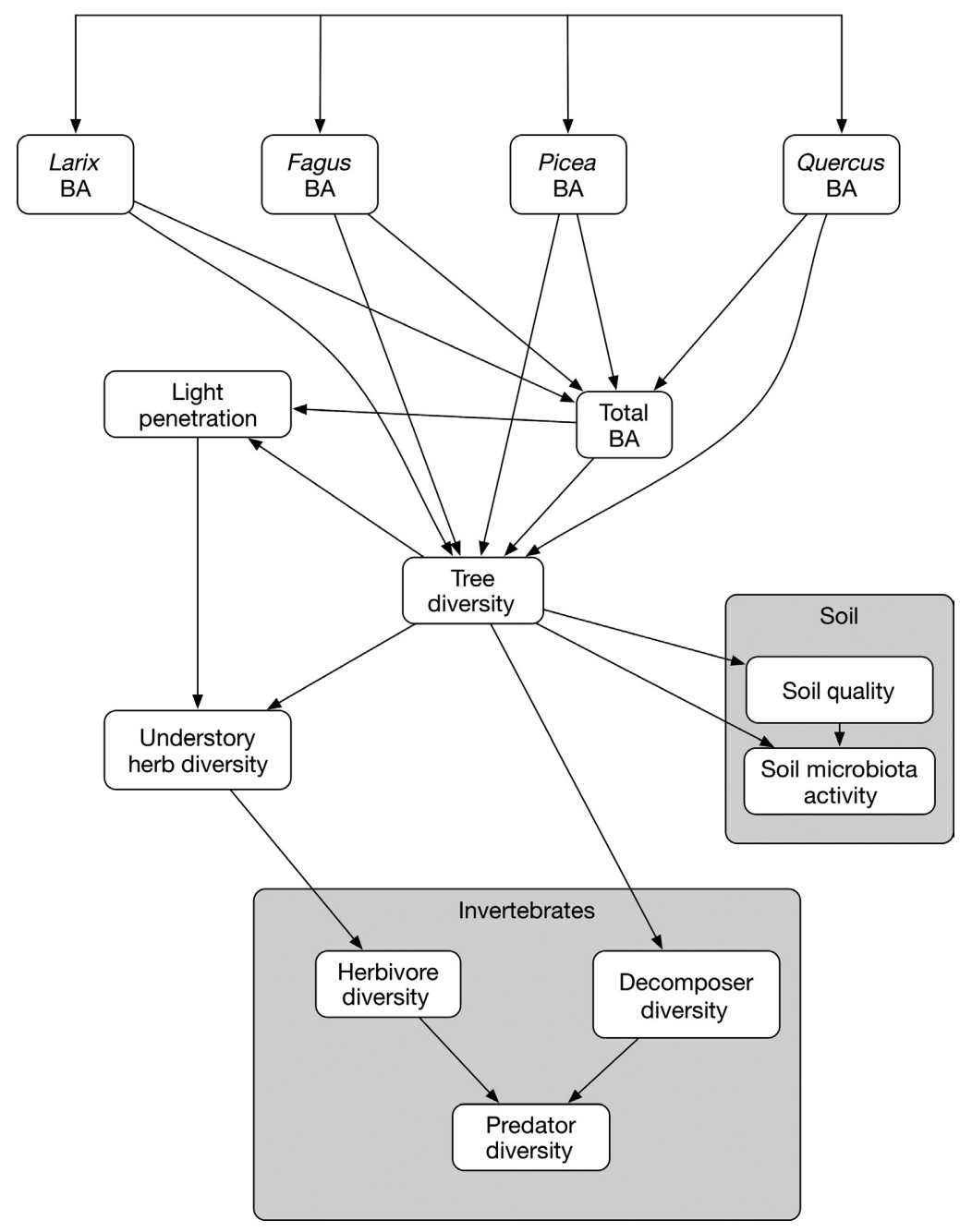

FIG. 2. The a priori causal model of relationships between concepts (independent of data availability). The arrows in this diagram represent a hypothesized direct causal effect of the variable at the end of the arrow on the variable at the tip of the arrow. Double headed arrows, such that those connecting tree basal areas, indicate correlation due to unmeasured shared causes. Basal area (BA) is a measure of the absolute abundance of each tree species.

stand, range $0-4$ ), and 128 beetle species (mean 8.7, range 3-16), of which 42 were detritivores (mean 2.8, range $0-11$ ), 37 were predators (mean 2.4, range $0-5$ ), 30 were herbivores (mean 2.2, range $0-5$ ), and 19 were saproxylics (mean 0.9 , range $0-4$ ).

\section{Model selection}

Our initial causal network model was poorly supported by the data and was rejected $\left(\chi^{2}=208.9, \mathrm{df}=126, P<0.001\right.$, $\mathrm{AIC}=2503.6)$; the tests of conditional independence were predicted from the initial model in Table S2 (Appendix S1). Of the 63 conditional independence tests indicated by the missing pairwise links in the initial model, nine failed (i.e., $P<0.05)$. Six of these nine represented species-specific effects on other variables; specifically soil quality, understory herb richness, canopy cover, and detritus. We used this feedback to modify the original causal network
(Appendix S1: Fig. S2). Including the links indicated in Fig. $\mathrm{S} 2$ (Appendix S1) resolved the discrepancy between the model and the data $\left(\chi^{2}=94.1, \mathrm{df}=112, P=0.889\right)$. To arrive at the final data-informed model, we removed the links for which there was little statistical support (Fig. 3). The hypothesis that the data were generated by a causal structure shown in Fig. 3 could not be rejected $\left(\chi^{2}=104.9\right.$, df $=124, P=0.891$, AIC $=2,436.6$ ). The final parameter estimates are shown in Table 1, and the corresponding relationships are depicted in Fig. S3 (Appendix S1). The results of the conditional independence test for this final model are shown in Table S3 (Appendix S1).

\section{Effects on understory}

Herbs.-Understory herb richness increased with increasing soil quality, and decreased with canopy cover and Larix basal area (standardized coefficients 
$[\mathrm{SC}]=0.11,-1.75$, and -0.06 , respectively, $R^{2}=0.56$ ). Increasing Fagus basal area further reduced herb species richness $(\mathrm{SC}=-0.09)$ by increasing canopy cover (SC $=0.05$ ). Picea and Quercus basal area also had indirect effects on herb species richness ( $\mathrm{SC}=-0.02$ and 0.02 , respectively), which were mediated by their negative (Picea) and positive (Quercus) effects on soil quality $\left(\mathrm{SC}=-0.20\right.$ and 0.18 , respectively, $R^{2}=0.43$ ). Contrary to our expectations, tree diversity had no net direct or indirect effect on herb species richness.

Invertebrates. - The diversity of saproxylic beetles and earthworms was positively and solely affected by tree diversity ( $\mathrm{SC}=0.35, R^{2}=0.15$ for saproxylic beetles, $\mathrm{SC}=0.18, R^{2}=0.10$ for earthworms). Increasing soil quality and Larix basal area reduced the diversity of detritivorous beetles ( $\mathrm{SC}=-0.28$ and -0.1 , respectively). We found no support for the hypothesized effects of herb diversity on herbivore diversity, or for herbivore and decomposer diversity on predator diversity.

\section{Discussion}

Using a fully replicated study design and an appropriate analysis, we demonstrate that tree diversity promoted the species richness of earthworms and saproxylic beetles, but contrary to our expectations, did not affect the diversity of other invertebrate groups or understory herbs (Fig. 3). To our knowledge, this is the first multitaxon study to distinguish the effects of diversity from those of tree identity, and to account for the potentially confounding effects of environmental heterogeneity (Nadrowski et al. 2010).

\section{Effects on invertebrate diversity}

We found that tree diversity had direct positive effects on the diversity of earthworms and saproxylic beetles, whereas, surprisingly, it was independent of tree identity, abiotic conditions, and stand properties. A positive effect of tree diversity on earthworms was also found by Cesarz et al. (2007) in natural forests, who reasoned that increasing litter diversity increased the diversity of food available to earthworms. In contrast, Schwarz et al. (2015) found a weak effect of tree identity, but no effect of tree diversity, on earthworm species richness. However, their study was carried in forest stands so young ( $8-10$ years old) that the trees might have had insufficient time to generate the changes in soil properties that would facilitate higher earthworm diversity. In addition, the tree-identity effect in their study was site-specific and limited to two of 18 tree species. In combination with our results, this suggests that earthworm diversity is largely independent of tree identity. Similarly, the species richness of saproxylic beetles has been found to increase with dead wood diversity (Similä et al. 2003), which is likely to correlate with tree species diversity. Surprisingly, we found no relationship between tree and detritivore diversity, even though trees are the main producers of leaf litter. This lack of effect could have arisen if the detritivorous beetles were generalist consumers, and therefore not as responsive to litter composition and diversity as saproxylic beetles or earthworms (Lassau et al. 2005).

Detritivore beetles were the only group of invertebrates whose diversity was significantly affected by tree identity and abiotic conditions. Their species richness decreased with soil quality and with increasing Larix abundance. The effect of Larix is likely to be caused by unfavorable properties of its litter, which has higher $\mathrm{N}$ immobilization and lower concentrations of $\mathrm{Ca}$ and $\mathrm{K}$ compared to the other studied tree species (Hobbie et al. 2006). The mechanism behind the negative effect of soil quality is less clear. We represented soil quality in our model as the positions along the first axis of PCA containing all measured soil attributes. Values on this axis correlated positively with $\mathrm{pH}$ and $\mathrm{N}$ content, and negatively with humus mass. Therefore, the negative effect of soil quality could imply a positive effect of humus mass on detritivore diversity, probably because of an increase in the amount of detritus on which this group feeds. In addition, greater amounts of slowly decomposing humus are likely to moderate the temporal variation in soil temperature and humidity, and are less likely to completely decompose or be removed by soil disturbances. This, in turn, might provide a more stable environment for detritivore beetles, and therefore promote their diversity. Surprisingly, the difference in litter quality caused by differences in species identity did not affect earthworm or saproxylic beetle diversity, though tree diversity did. We speculate that this could happen if earthworm and saproxylic beetle species were more specific to certain tree species, and if all tree species hosted the same average number of invertebrates. Finally, the lack of significant relationships between understory diversity and most of the abiotic factors we measured may be attributable to the minimal variation captured in our study. We selected our 45 study stands to be as similar as possible in terms of altitude, topology, and soil type, which limited our power to detect the effects of soil characteristics on the diversity of understory taxa.

\section{Tree effects on herb diversity}

We found that herb diversity was most strongly affected by canopy cover and more weakly by tree identity and soil quality, but not, contrary to our prediction, by tree diversity (Fig. 3). We had also expected herb diversity to be reduced by tree diversity because diverse forests tend to have more densely packed canopies and thus greater canopy cover (Jucker et al. 2015). In this study, we found a positive relationship between total stand basal area and canopy cover. Because this basal area measurement is calculated from the basal areas of the measured tree species, it is not an independent variable and we could not test for the relationship between tree diversity and total basal area 


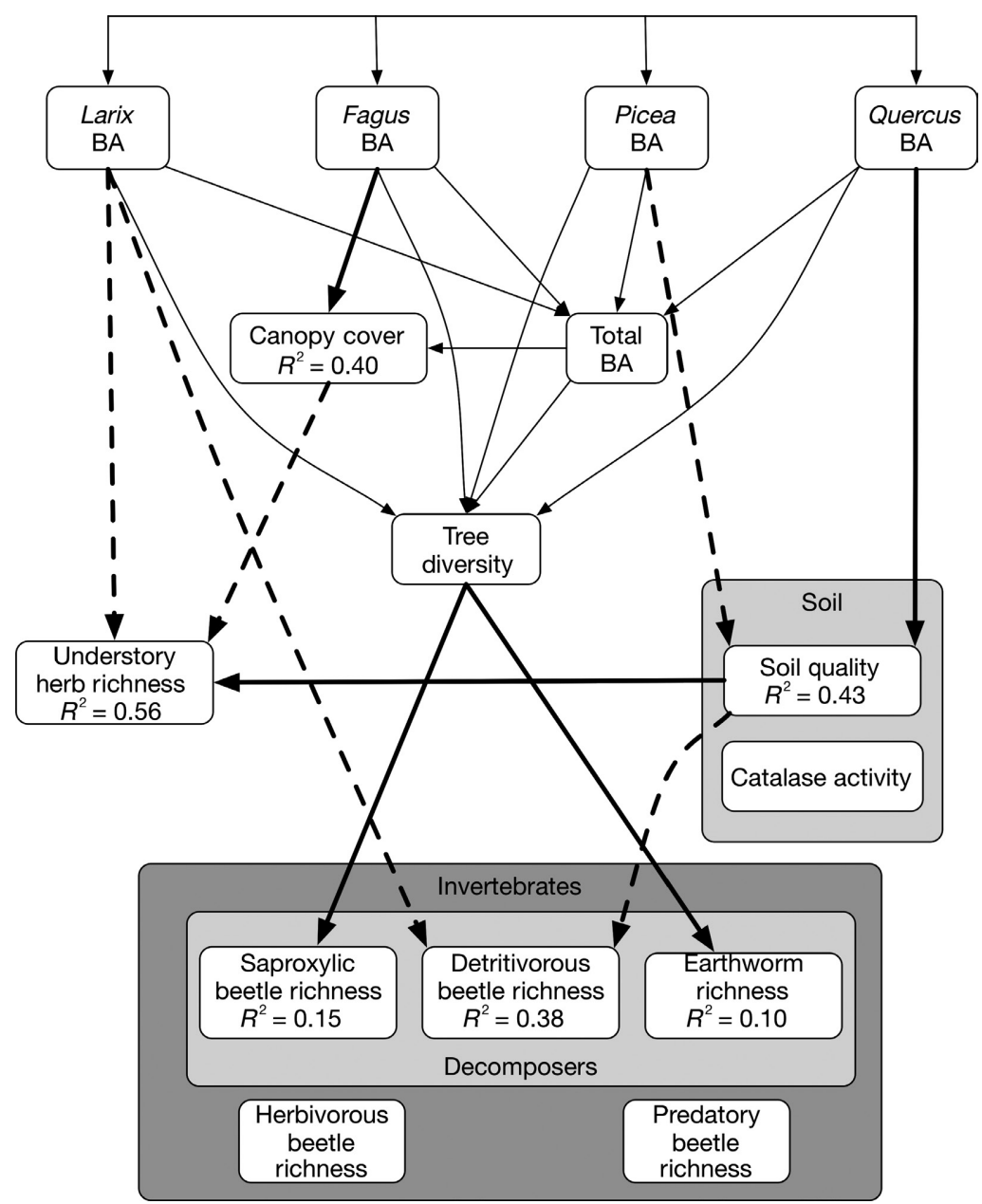

FIG. 3. The final model $\left(\chi^{2}=104.9, \mathrm{df}=124, P=0.891\right)$. Only relationships found to be statistically significant $(P<0.05)$ were retained. Percentage variance explained $\left(R^{2}\right)$ is shown for random variables, i.e., the variables that were predicted from the model.

that other studies have reported (Paquette and Messier 2011, Barrufol et al. 2013, Vilà et al. 2013). It has been found that forests with high tree diversity have greater structural complexity and canopies that capture more light (Morin et al. 2011). This, in turn, reduces the amount of light reaching the understory, which limits herb growth and decreases herb diversity (Kirby 1988, Jennings et al. 1999, Barbier et al. 2008). Although this causal reasoning makes intuitive sense, it contradicts previous studies that detected positive or neutral effects of tree diversity on herb diversity (Ingerpuu et al. 2003, Mölder et al. 2008, Nadrowski et al. 2010, Vockenhuber et al. 2011). Those studies, however, were carried out in natural or seminatural forests, where variation in abiotic conditions has the potential to confound the effects of tree diversity on herb diversity (Vockenhuber et al. 2011).

Our study confirms that abiotic conditions affect understory herb species richness (Barbier et al. 2008). We showed that herb diversity not only decreases with increasing canopy cover, but also with humus mass, corroborating research from other temperate forests
(Augusto et al. 2003, Gazol and Ibáñez 2009, Vockenhuber et al. 2011). The humus layer represents a physical barrier for germinating plants (Sydes and Grime 1981, Dzwonko and Gawroński 2002). Naturally, the tree species with greatest effects on canopy cover and humus most strongly affected herb diversity. For example, Fagus sylvatica is one of the most shade-casting species in European forests (Brzeziecki and Kienast 1994), and an increase in its abundance indirectly decreased herb diversity via its positive effect on canopy cover. Quercus petraea, on the other hand, produces a quickly decomposing litter (Cornelissen 1996), and its abundance indirectly enhanced herb diversity via its positive effect on soil quality, corresponding to a negative effect on humus mass.

\section{CONCLUSIONS AND IMPLICATIONS FOR FORESTRY}

Understanding the mechanisms underlying the effects of trees on the understory can help us manage forests to simultaneously maximize multiple ecosystem functions. The positive effect of tree diversity on the diversity of 
TABLE 1. All coefficients in the final model, linking the response variables (rows) to all significant explanatory variables (columns).

\begin{tabular}{|c|c|c|c|c|c|c|c|c|c|c|}
\hline $\begin{array}{l}\text { Response } \\
\text { variable }\end{array}$ & $\begin{array}{l}\text { Distribution } \\
\quad \text { (link) }\end{array}$ & Intercept & $\begin{array}{c}\text { Larix } \\
\mathrm{BA}\end{array}$ & $\begin{array}{l}\text { Fagus } \\
\text { BA }\end{array}$ & $\begin{array}{l}\text { Picea } \\
\text { BA }\end{array}$ & $\begin{array}{l}\text { Quercus } \\
\text { BA }\end{array}$ & $\begin{array}{l}\text { Total } \\
\text { BA }\end{array}$ & $\begin{array}{c}\text { Tree } \\
\text { diversity }\end{array}$ & $\begin{array}{l}\text { Canopy } \\
\text { cover }\end{array}$ & $\begin{array}{c}\text { Soil } \\
\text { quality }\end{array}$ \\
\hline Canopy cover & $\begin{array}{c}\text { normal } \\
(\log )\end{array}$ & $-3.28 \times 10^{-1}$ & & $\begin{array}{r}4.63 \\
\times 10^{-2}\end{array}$ & & & $\begin{array}{r}1.20 \\
\times 10^{-3}\end{array}$ & & & \\
\hline Soil quality & $\begin{array}{c}\text { normal } \\
\text { (identity) }\end{array}$ & $1.44 \times 10^{-1}$ & & & $\begin{array}{r}-2.04 \\
\times 10^{-1}\end{array}$ & $\begin{array}{r}1.81 \\
\times 10^{-1}\end{array}$ & & & & \\
\hline Catalase activity & $\begin{array}{l}\text { normal } \\
\text { (identity) }\end{array}$ & $6.99 \times 10^{1}$ & & & & & & & & \\
\hline $\begin{array}{l}\text { Understory herb } \\
\text { richness }\end{array}$ & $\begin{array}{c}\text { negative } \\
\text { binomial (log) }\end{array}$ & $4.81 \times 10^{0}$ & $\begin{array}{r}-6.10 \\
\times 10^{-2}\end{array}$ & & & & & & $\begin{array}{l}-1.75 \\
\times 10^{0}\end{array}$ & $\begin{array}{r}1.14 \\
\times 10^{-1}\end{array}$ \\
\hline $\begin{array}{l}\text { Herbivorous } \\
\text { beetle richness }\end{array}$ & $\begin{array}{c}\text { Poisson } \\
\text { (log) }\end{array}$ & $7.68 \times 10^{-1}$ & & & & & & & & \\
\hline $\begin{array}{l}\text { Saproxylic } \\
\text { beetle richness }\end{array}$ & Poisson (log) & $-1.07 \times 10^{0}$ & & & & & & $\begin{array}{r}3.49 \\
\times 10^{-1}\end{array}$ & & \\
\hline $\begin{array}{l}\text { Detritivorous } \\
\text { beetle } \\
\text { richness }\end{array}$ & $\begin{array}{c}\text { negative } \\
\text { binomial (log) }\end{array}$ & $1.17 \times 10^{0}$ & $\begin{array}{r}-9.97 \\
\times 10^{-2}\end{array}$ & & & & & & & $\begin{array}{r}-2.79 \\
\times 10^{-1}\end{array}$ \\
\hline $\begin{array}{l}\text { Earthworm } \\
\text { richness }\end{array}$ & $\begin{array}{l}\text { Poisson } \\
\log )\end{array}$ & $3.81 \times 10^{-1}$ & & & & & & $\begin{array}{r}1.76 \\
\times 10^{-1}\end{array}$ & & \\
\hline $\begin{array}{l}\text { Predatory beetle } \\
\text { richness }\end{array}$ & $\begin{array}{l}\text { Poisson } \\
\text { (log) }\end{array}$ & $8.85 \times 10^{-1}$ & & & & & & & & \\
\hline
\end{tabular}

Notes: All coefficients in bold were significant in the model. The coefficients for explanatory variables that didn't have any effect on the response variables (i.e., catalase activity, understory herb richness, herbivorous beetle richness, saproxylic beetle richness, detritivorous beetle richness, earthworm richness, and predatory beetle richness) are not shown in the table. The distribution error models (associated with the link function) are given for each response variable. BA, basal area.

earthworms and saproxylic beetles is likely to affect nutrient cycling and soil formation (Hättenschwiler et al. 2005, Cobb et al. 2010). By altering the composition and activity of soil biota (Scheu et al. 2002), earthworms and saproxylic beetles support the structure and functioning of the aboveground community, including plant growth and productivity (Wardle et al. 2004). On the other hand, tree identity significantly affected the diversity of herbs and detritivorous beetles, but not that of saproxylic beetles and earthworms. This implies that changes in tree species composition would not affect the diversity of earthworms and saproxylic beetles as long as tree diversity stayed unchanged, whereas herb diversity would vary since it is highly dependent on tree identity. In addition, except for the effect of Quercus on herb diversity, all tree identity effects were negative. This implies that avoiding planting or keeping low density of some tree species, such as Larix decidua, which was also the only nonnative species of our study, may benefit several understory taxa. Therefore, encouraging high tree diversity in planted forests may be beneficial not only for timber production (J. Chamagne et al., unpublished manuscript) but also for forest biodiversity, which can be further promoted by the careful selection of tree species. Indeed, we recommend maintaining high tree diversity overall, while maintaining at low abundance tree species that may detrimentally impact understory diversity.

\section{AcKnowledgments}

This study was funded by the grant number F-74330-02-01 to Andy Hector from the "Stiftung für wissenschaftliche Forschung an der Universität Zürich," by the University of Zürich, and by a project of the Ministry of Education, Youth, and Sports of the Czech Republic: LG12018 "Involvement of the Czech Republic in international research of the European Forest Institute (EFI)."

\section{Statement of Authorship}

The authors declare no conflict of interest. J. Chamagne, C. E. Timothy Paine, D. Volařík, A. Hector, and R. Matula designed the research; J. Chamagne, C. E. Timothy Paine, R. Stejskal, D. Volařík, J. Šebesta, F. Trnka, T. Koutecký, P. Švarc, M. Svátek, and R. Matula conducted the research; J. Chamagne, C. E. Timothy Paine, D. R. Schoolmaster, R. Stejskal, D. Volařík, F. Trnka, A. Hector, and R. Matula contributed to the analyses and interpretation; and J. Chamagne, C. E. Timothy Paine, D. R. Schoolmaster, A. Hector, and R. Matula wrote the manuscript.

\section{Literature Cited}

Aerts, R. 1997. Climate, leaf litter chemistry and leaf litter decomposition in terrestrial ecosystems: a triangular relationship. Oikos 79:439-449.

Augusto, L., J. L. Dupouey, and J. Ranger. 2003. Effects of tree species on understory vegetation and environmental conditions in temperate forests. Annals of Forest Science 60:823-831.

Barbier, S., F. Gosselin, and P. Balandier. 2008. Influence of tree species on understory vegetation diversity and mechanisms involved - a critical review for temperate and boreal forests. Forest Ecology and Management 254:1-15.

Barrufol, M., B. Schmid, H. Bruelheide, X. Chi, A. Hector, K. Ma, S. Michalski, Z. Tang, and P. A. Niklaus. 2013. Biodiversity promotes tree growth during succession in subtropical forest. PLoS ONE 8:e81246.

Brzeziecki, B., and F. Kienast. 1994. Classifying the life-history strategies of trees on the basis of the Grimian model. Forest Ecology and Management 69:167-187. 
Cardinale, B. J., et al. 2012. Biodiversity loss and its impact on humanity. Nature 486:59-67.

Cesarz, S., N. Fahrenholz, S. Migge-Kleian, C. Platner, and M. Schaefer. 2007. Earthworm communities in relation to tree diversity in a deciduous forest. European Journal of Soil Biology 43:S61-S67.

Cobb, T. P., K. D. Hannam, B. E. Kishchuk, D. W. Langor, S. A. Quideau, and J. R. Spence. 2010. Wood-feeding beetles and soil nutrient cycling in burned forests: implications of post-fire salvage logging. Agricultural and Forest Entomology 12:9-18.

Cornelissen, J. H. C. 1996. An experimental comparison of leaf decomposition rates in a wide range of temperate plant species and types. Journal of Ecology 84:573-582.

Dzwonko, Z., and S. Gawroński. 2002. Influence of litter and weather on seedling recruitment in a mixed oak-pine woodland. Annals of Botany 90:245-251.

Fisher, R. A. 1950. Statistical methods for research workers. Hafner, New York, New York, USA.

Gazol, A., and R. Ibáñez. 2009. Different response to environmental factors and spatial variables of two attributes (cover and diversity) of the understorey layers. Forest Ecology and Management 258:1267-1274.

Gilliam, F. S. 2006. Response of the herbaceous layer of forest ecosystems to excess nitrogen deposition. Journal of Ecology 94:1176-1191.

Gilliam, F. S. 2007. The ecological significance of the herbaceous layer in temperate forest ecosystems. BioScience 57:845-858.

Grace, J. B. 2006. Structural equation modeling and natural systems. Cambridge University Press, New York, New York, USA.

Hättenschwiler, S., A. V. Tiunov, and S. Scheu. 2005. Biodiversity and litter decomposition in terrestrial ecosystems. Annual Review of Ecology, Evolution, and Systematics 36:191-218

Hobbie, S. E., P. B. Reich, J. Oleksyn, M. Ogdahl, R. Zytkowiak, C. Hale, and P. Karolewski. 2006. Tree species effects on decomposition and forest floor dynamics in a common garden. Ecology 87:2288-2297.

Hofmeister, J., J. Hošek, M. Modrý, and J. Roleček. 2009. The influence of light and nutrient availability on herb layer species richness in oak-dominated forests in central Bohemia. Plant Ecology 205:57-75.

Hooper, D. U., E. C. Adair, B. J. Cardinale, J. E. K. Byrnes, B. A. Hungate, K. L. Matulich, A. Gonzalez, J. E. Duffy, L. Gamfeldt, and M. I. O'Connor. 2012. A global synthesis reveals biodiversity loss as a major driver of ecosystem change. Nature 486:105-108.

Ingerpuu, N., K. Vellak, J. Liira, and M. Pärtel. 2003. Relationships between species richness patterns in deciduous forests at the north Estonian limestone escarpment. Journal of Vegetation Science 14:773-780.

Jennings, S. B., N. D. Brown, and D. Sheil. 1999. Assessing forest canopies and understorey illumination: canopy closure, canopy cover and other measures. Forestry 72:59-73.

Jucker, T., O. Bouriaud, D. Avacaritei, and D. A. Coomes. 2014. Stabilizing effects of diversity on aboveground wood production in forest ecosystems: linking patterns and processes. Ecology Letters 17:1560-1569.

Jucker, T., O. Bouriaud, and D. A. Coomes. 2015. Crown plasticity enables trees to optimize canopy packing in mixedspecies forests. Functional Ecology 29:1078-1086.

Kirby, K. J. 1988. Changes in the ground flora under plantations on ancient woodland sites. Forestry 61:317-338.

Lassau, S., D. Hochuli, G. Cassis, and C. Reid. 2005. Effects of habitat complexity on forest beetle diversity: Do functional groups respond consistently? Diversity and Distributions 11:73-82.
Loreau, M., and A. Hector. 2001. Partitioning selection and complementarity in biodiversity experiments. Nature 412:72-76.

Magurran, A. E. 2004. Measuring biological diversity. Blackwell Publishing, Oxford, UK.

Mölder, A., M. Bernhardt-Römermann, and W. Schmidt. 2008. Herb-layer diversity in deciduous forests: Raised by tree richness or beaten by beech? Forest Ecology and Management 256:272-281.

Morin, X., L. Fahse, M. Scherer-Lorenzen, and H. Bugmann. 2011. Tree species richness promotes productivity in temperate forests through strong complementarity between species. Ecology Letters 14:1211-1219.

Muller, R. N. 2003. Nutrient relations of the herbaceous layer in deciduous forest ecosystems. Pages 15-37 in F. S. Gilliam and M. R. Roberts, editors. The herbaceous layer in forests of eastern North America. Oxford University Press, New York, New York, USA.

Nadrowski, K., C. Wirth, and M. Scherer-Lorenzen. 2010. Is forest diversity driving ecosystem function and service? Current Opinion in Environmental Sustainability 2:75-79.

Naeem, S., D. E. Bunker, A. Hector, M. Loreau, and C. Perrings. 2009. Biodiversity, ecosystem functioning, and human wellbeing: an ecological and economic perspective. Oxford University Press, New York, New York, USA.

Paquette, A., and C. Messier. 2011. The effect of biodiversity on tree productivity: from temperate to boreal forests. Global Ecology and Biogeography 20:170-180.

Partsch, S., A. Milcu, and S. Scheu. 2006. Decomposers (Lumbricidae, Collembola) affect plant performance in model grasslands of different diversity. Ecology 87:2548-2558.

Ponge, J.-F., N. Patzel, L. Delhaye, E. Devigne, C. Levieux, P. Beros, and R. Wittebroodt. 1999. Interactions between earthworms, litter and trees in an old-growth beech forest. Biology and Fertility of Soils 29:360-370.

R Development Core Team. 2011. R: a language and environment for statistical computing. R Foundation for Statistical Computing, Vienna, Austria. https://www.r-project.org

Rockström, J., et al. 2009. A safe operating space for humanity. Nature 461:472-475.

Scheu, S. 2003. Effects of earthworms on plant growth: patterns and perspectives. Pedobiologia 47:846-856.

Scheu, S., N. Schlitt, A. Tiunov, J. Newington, and H. Jones. 2002. Effects of the presence and community composition of earthworms on microbial community functioning. Oecologia 133:254-260.

Schmidt, O., J. P. Curry, J. Dyckmans, E. Rota, and C. M. Scrimgeour. 2004. Dual stable isotope analysis $(\delta 13 \mathrm{C}$ and $\delta$ $15 \mathrm{~N}$ ) of soil invertebrates and their food sources. Pedobiologia 48:171-180.

Schwarz, B., C. Dietrich, S. Cesarz, M. Scherer-Lorenzen, H. Auge, E. Schulz, and N. Eisenhauer. 2015. Non-significant tree diversity but significant identity effects on earthworm communities in three tree diversity experiments. European Journal of Soil Biology 67:17-26.

Shipley, B. 2000. Cause and correlation in biology. Cambridge University Press, Cambridge, UK.

Shtatland, E. S., and M. B. Barton. 1998. An information-gain measure of fit in PROC LOGISTIC. Pages 1194-1199. in SUGI'98 Proceedings. SAS Institute Inc., Cary, North Carolina, USA.

Similä, M., J. Kouki, and P. Martikainen. 2003. Saproxylic beetles in managed and seminatural Scots pine forests: quality of dead wood matters. Forest Ecology and Management 174:365-381.

Sobek, S., M. M. Goßner, C. Scherber, I. Steffan-Dewenter, and T. Tscharntke. 2009a. Tree diversity drives abundance and spatiotemporal $\beta$-diversity of true bugs (Heteroptera). Ecological Entomology 34:772-782. 
Sobek, S., I. Steffan-Dewenter, C. Scherber, and T. Tscharntke. 2009b. Spatiotemporal changes of beetle communities across a tree diversity gradient. Diversity and Distributions 15:660-670.

Sydes, C., and J. Grime. 1981. Effects of tree leaf litter on herbaceous vegetation in deciduous woodland: I. Field investigations. Journal of Ecology 69:237-248.

Truhlář, J. 1997. Silviculture in biological conception : a guide around the Training Forest Enterprise "Masaryk Forest" at Krrtiny. Mendel University of Agriculture and Forestry, Brno, Czech Republic.

van der Heijden, M. G. A., R. D. Bardgett, and N. M. van Straalen. 2008. The unseen majority: soil microbes as drivers of plant diversity and productivity in terrestrial ecosystems. Ecology Letters 11:296-310.

Venables, W. N., and B. D. Ripley. 2002. Modern applied statistics with S. Fourth edition. Springer, New York, New York, USA.

Vilà, M., A. Carrillo-Gavilán, J. Vayreda, H. Bugmann, J. Fridman, W. Grodzki, J. Haase, G. Kunstler, M. Schelhaas, and A. Trasobares. 2013. Disentangling biodiversity and climatic determinants of wood production. PLoS ONE 8:e53530.

Vockenhuber, E. A., C. Scherber, C. Langenbruch, M. Meißner, D. Seidel, and T. Tscharntke. 2011. Tree diversity and environmental context predict herb species richness and cover in Germany's largest connected deciduous forest. Perspectives in Plant Ecology, Evolution and Systematics 13:111-119.

Wardle, D. A. 1999. How soil food webs make plants grow. Trends in Ecology \& Evolution 14:418-420.

Wardle, D. A., R. D. Bardgett, J. N. Klironomos, H. Setälä, W. H. van der Putten, and D. H. Wall. 2004. Ecological linkages between aboveground and belowground biota. Science 304:1629-1633.

Wurst, S., R. Langel, A. Reineking, M. Bonkowski, and S. Scheu. 2003. Effects of earthworms and organic litter distribution on plant performance and aphid reproduction. Oecologia 137:90-96.

Zhang, Y., H. Y. H. Chen, and P. B. Reich. 2012. Forest productivity increases with evenness, species richness and trait variation: a global meta-analysis. Journal of Ecology 100:742-749.

\section{SUPPORTING INFORMATION}

Additional supporting information may be found in the online version of this article at http://onlinelibrary.wiley.com/ doi/10.1002/ecy.1479/suppinfo 